\title{
The relative impact of cloud condensation nuclei and ice nucleating particle concentrations on phase partitioning in Arctic mixed-phase stratocumulus clouds
}

\author{
Amy Solomon $^{1,2}$, Gijs de Boer ${ }^{1,2}$, Jessie M. Creamean ${ }^{1,2, a}$, Allison McComiskey ${ }^{2}$, Matthew D. Shupe ${ }^{1,2}$, \\ Maximilian Maahn ${ }^{1,2}$, and Christopher Cox ${ }^{1,2}$ \\ ${ }^{1}$ Cooperative Institute for Research in Environmental Sciences, University of Colorado, Boulder, Colorado, USA \\ ${ }^{2}$ Earth System Research Laboratory, National Oceanic and Atmospheric Administration, Boulder, Colorado, USA \\ ${ }^{a}$ now at: Department of Atmospheric Sciences, Colorado State University, Fort Collins, Colorado, USA
}

Correspondence: Amy Solomon (amy.solomon@noaa.gov)

Received: 12 July 2018 - Discussion started: 10 August 2018

Revised: 25 October 2018 - Accepted: 12 November 2018 - Published: 3 December 2018

\begin{abstract}
This study investigates the interactions between cloud dynamics and aerosols in idealized large-eddy simulations (LES) of Arctic mixed-phase stratocumulus clouds (AMPS) observed at Oliktok Point, Alaska, in April 2015. This case was chosen because it allows the cloud to form in response to radiative cooling starting from a cloud-free state, rather than requiring the cloud ice and liquid to adjust to an initial cloudy state. Sensitivity studies are used to identify whether there are buffering feedbacks that limit the impact of aerosol perturbations. The results of this study indicate that perturbations in ice nucleating particles (INPs) dominate over cloud condensation nuclei $(\mathrm{CCN})$ perturbations; i.e., an equivalent fractional decrease in $\mathrm{CCN}$ and INPs results in an increase in the cloud-top longwave cooling rate, even though the droplet effective radius increases and the cloud emissivity decreases. The dominant effect of ice in the simulated mixed-phase cloud is a thinning rather than a glaciation, causing the mixed-phase clouds to radiate as a grey body and the radiative properties of the cloud to be more sensitive to aerosol perturbations. It is demonstrated that allowing prognostic $\mathrm{CCN}$ and INPs causes a layering of the aerosols, with increased concentrations of $\mathrm{CCN}$ above cloud top and increased concentrations of INPs at the base of the cloud-driven mixed layer. This layering contributes to the maintenance of the cloud liquid, which drives the dynamics of the cloud system.
\end{abstract}

\section{Introduction}

Arctic mixed-phase stratocumulus clouds (AMPS) play a unique role in climate by producing a net warming at the Earth's surface over the annual cycle. This warming is due to the limited amount of incoming solar radiation at high latitudes, causing downward longwave radiative effects to dominate surface cloud forcing in the Arctic. AMPS are characterized by a liquid cloud layer with ice crystals that precipitate from cloud base even at temperatures well below freezing (Hobbs and Rangno, 1998; Intrieri et al., 2002; McFarquhar et al., 2007). The magnitude of the cloud-forced surface warming is primarily a function of the liquid water content of the AMPS and the properties of the cloud droplets (Curry and Ebert, 1992; Curry et al., 1993; Zhang et al., 1996). However, different from warm clouds, the magnitude and properties of cloud liquid in mixed-phase clouds are closely connected to the formation of cloud ice, which limits the availability of water vapor for droplet formation and growth (the Wegener-Bergeron-Findeisen, WBF, mechanism, Wegener, 1911; Bergeron, 1935; Findeisen, 1938) and acts as a sink for water vapor through the growth and sedimentation of frozen precipitation.

Cloud ice in AMPS must form through heterogeneous nucleation, since temperatures are too warm for homogenous ice nucleation (approximately $>36^{\circ} \mathrm{C}$ ). Heterogeneous ice nucleation can occur by a number of modes: either in the presence of supercooled droplets, when an aerosol comes into contact with a droplet (contact freezing) and is immersed 
in a droplet followed by freezing (immersion freezing), or in the absence of droplets through vapor deposition on aerosol (deposition freezing) or liquid forming on aerosol (condensation freezing) (Pruppacher and Klett, 1997). The efficiency of any of these modes in a given environmental state is a function of aerosol properties, which determine whether an aerosol can serve as an ice nucleating particle (INP), cloud condensation nuclei (CCN), or both. Based on measurements from in situ instrumentation and the reduced concentration of ice crystals relative to liquid droplets (Murray et al., 2012), it is believed that only a small fraction of aerosols can serve as INPs. For example, in the Indirect and Semi-Direct Aerosol Campaign (ISDAC) (McFarquhar et al., 2011) that took place off the coast of Utqiagivik, (Barrow) Alaska, in the spring of 2008, the number of INPs available were observed to be 4 orders of magnitude smaller than the number of aerosols serving as CCN. However, it is important to note that only a few INPs are needed to glaciate a cloud (see discussion in DeMott et al., 2010).

The impact of $\mathrm{CCN}$ variability on warm cloud structure has been the subject of numerous papers. For a fixed liquid water path (LWP), an increase in CCN in warm clouds will increase the number of droplets and reduce the droplet size. This causes an increase in cloud albedo (the Twomey effect; Twomey, 1977) and potentially suppresses precipitation (the Albrecht effect; Albrecht, 1989). Suppressing precipitation can increase cloud thickness/coverage and clouddriven turbulence, which increases the entrainment of dry air at cloud top, thereby thinning the cloud (Pincus and Baker, 1994; Stevens et al., 1998). This thinning of the cloud as a response to an increase in aerosols is an example of a buffering feedback that limits the impact of a CCN perturbation on the cloud structure (Stevens and Feingold, 2009). For LWPs greater than approximately $50 \mathrm{~g} \mathrm{~m}^{-2}$, AMPS emit as blackbodies (Shupe and Intrieri, 2004) and an increase in CCN has minimal impact on longwave emissivity (Morrison et al., 2008). However, smaller droplets can also reduce the ice water path (IWP) through a reduction in collision-coalescence and riming of snow by droplets (Morrison et al., 2008) as well as make ice nucleation less efficient (Lance et al., 2011). These are only a few examples of buffering feedbacks that exist in mixed-phase clouds.

An increase in INPs in AMPS is known to produce a "glaciation effect", i.e., a rapid depletion of cloud liquid, in part due to the WBF mechanism and the acceleration of frozen precipitation (Murray et al., 2012). However, the efficacy of this effect is dependent upon the chemical composition of the INPs. In cases where INPs are transported over long distances and coated in sulfate or organic materials, an increased concentration of INPs may actually be linked to a "deactivation effect". This is because coated particles generally freeze at colder temperatures (Cziczo et al., 2009; Sullivan et al., 2010; Girard and Sokhandan, 2014), changing the number, size, and fall speeds of nucleated ice crystals and increasing cloud lifetime. The deactivation effect can cause a significant increase in surface warming, since a decrease in droplet size in optically thin clouds for constant LWP can produce a significant increase in cloud longwave emissivity (Garrett and Zhao, 2006).

Given the uncertainty in measurements of INPs (DeMott et al., 2015; Garimella et al., 2017), it has been challenging to study the manifestation of aerosol-cloud interactions in mixed-phase cloud conditions. This study investigates these interactions and their dependence on aerosol partitioning in idealized large-eddy simulations (LES) of AMPS observed at Oliktok Point, Alaska, 05:00-17:00 Z on 17 April 2015. In order to isolate the impact of these interactions on longwave cloud forcing, shortwave radiation is neglected in the simulations. The microphysics used in Solomon et al. (2015) have been modified to include prognostic $\mathrm{CCN}$ in addition to prognostic INPs. This allows for a more realistic representation of aerosols advected over the Oliktok Point site. In order to identify aerosol indirect effects in these simulations, aerosol chemistry is specified and, due to the in-cloud temperatures for this case, all cloud ice forms through immersion freezing. The focus on immersion freezing is supported by studies demonstrating that liquid droplets typically form prior to ice formation in mixed-phase cloud environments (e.g., de Boer et al., 2011; Westbrook and Illingworth, 2013).

This study is focused on the following research questions:

1. What is the relative impact of CCN versus INP perturbations on the phase partitioning between cloud liquid and cloud ice in AMPS? Specifically, what is the impact on cloud dynamics?

2. Are there buffering feedbacks in AMPS that limit the impact of CCN-INP perturbations?

\section{Case description}

Simulations are set up to recreate conditions observed by the US Department of Energy (DOE) Atmospheric Radiation Measurement (ARM) program third mobile facility (AMF3) at Oliktok Point, Alaska, on and around 17 April 2015 (Fig. 1). During this time period, Oliktok Point was situated in a relatively quiet regime synoptically, with surface high pressure to the northwest over the Chukchi Sea and a weak area of low pressure over central Alaska. This resulted in steadily increasing surface air pressure from around $1008 \mathrm{hPa}$ at $00: 00 \mathrm{Z}$ on 16 April to around $1021 \mathrm{hPa}$ at 00:00 Z on 18 April and relatively light $\left(2-5 \mathrm{~m} \mathrm{~s}^{-1}\right)$ nearsurface winds $\left(U_{10 \mathrm{~m}}\right)$ from the east-northeast over this entire 2-day window (Fig. 1f, g). Near-surface air temperatures $\left(T_{2} \mathrm{~m}\right)$ varied dramatically (Fig. 1e), depending on time of day and cloud cover, with the coldest temperatures around $250 \mathrm{~K}$ during late evening and early morning clear periods on 16 April and the warmest temperatures being around $258 \mathrm{~K}$ during cloudy periods during local nighttime on 17 April. 

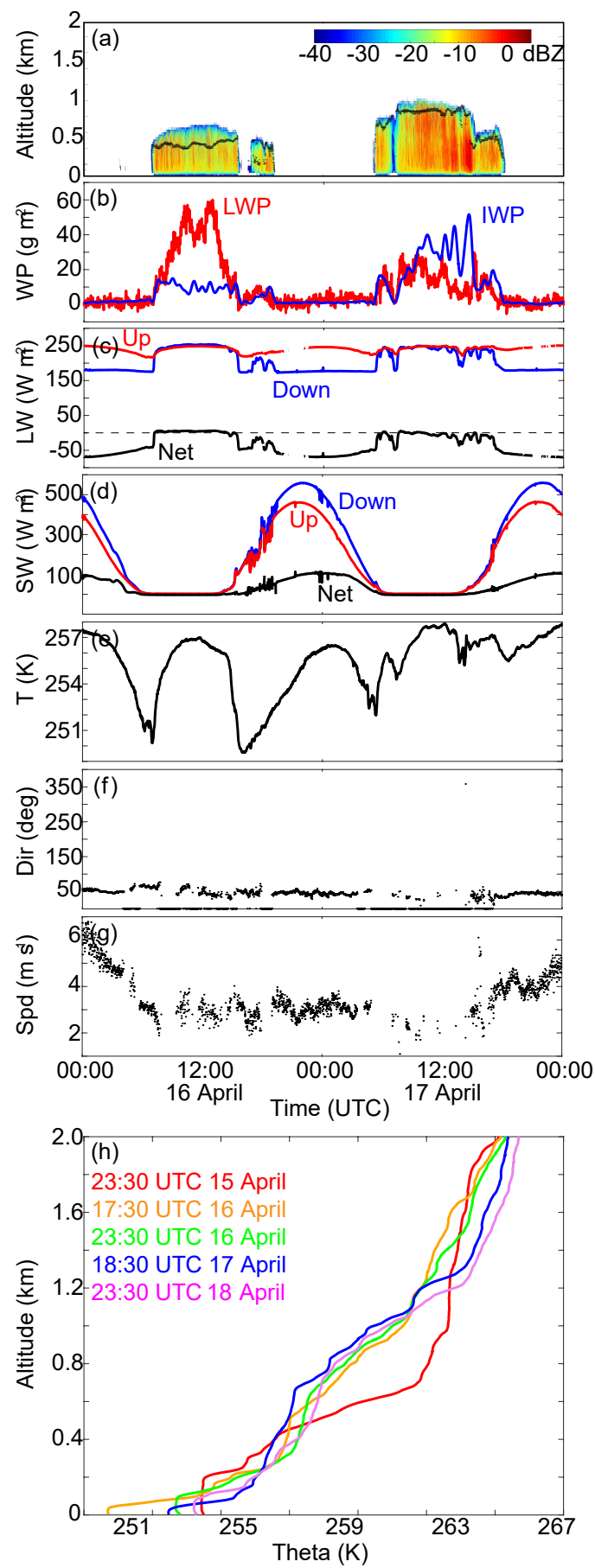

Figure 1. Measurements at Oliktok Point, Alaska, 15-17 April 2015. (a) Ceilometer (black dots) and Ka-band cloud radar reflectivity (colored shading). (b) LWP and IWP, in units of $\mathrm{g} \mathrm{m}^{-2}$. (c) LW and (d) SW surface radiation measurements, in units of $\mathrm{W} \mathrm{m}^{-2}$. (e) Surface air temperatures. (f) Surface wind direction, in units of degrees. (g) Surface wind speed, in units of $\mathrm{m} \mathrm{s}^{-1}$. (h) Radiosondes at approximately 23:30 UTC on 15 April, 17:30 and 23:30 UTC on 16 April, and 18:30 and 23:30 UTC on 17 April.

\section{Model description}

Simulations are completed using the large-eddy simulation mode of the Advanced Research WRF model (WRFLES) version 3.3.1 (Yamaguchi and Feingold, 2012) with 
the RRTMG longwave radiation parameterization (Mlawer et al., 1997) and the Morrison two-moment microphysical scheme (Morrison et al., 2009). Collision-coalescence was found to be important in $\mathrm{CCN}$ perturbation studies during the Fall 2004 Mixed-Phase Arctic Cloud Experiment (M-PACE; Morrison et al., 2008); however tests with and without riming and collision-coalescence indicated that these processes are not significant for this case and have been neglected in the simulations. Shortwave radiation is neglected given the nighttime occurrence of these clouds and to be able to focus on longwave indirect aerosol effects. Surface fluxes are calculated using the modified MM5 similarity scheme, which calculates surface exchange coefficients for heat, moisture, and momentum following Webb (1970) and uses MoninObukhov with Carlson-Boland viscous sublayer and standard similarity functions following Paulson (1970) and Dyer and Hicks (1970). The land surface is simulated with the unified Noah land-surface model (Tewari et al., 2004). Initial surface pressure is $1020 \mathrm{hPa}$. The initial surface temperature is $255 \mathrm{~K}$.

All simulations are run on a domain of $3.6 \times 3.6 \times 1.4 \mathrm{~km}$ with a horizontal grid spacing of $50 \mathrm{~m}$ and vertical spacing of $10 \mathrm{~m}$. The domain has $72(x) \times 72(y) \times 140(z)$ grid points and is periodic in both the $x$ and $y$ directions. The top of the domain is at $1.4 \mathrm{~km}$. The model time step is $0.5 \mathrm{~s}$.

\subsection{Initial atmospheric profiles}

Initial profiles of temperature, moisture, and horizontal wind components are based on radiosonde measurements taken at Oliktok Point at 23:30Z on 16 April 2015 (Fig. 1h). Soundings are not available during the cloudy period (05:0018:00 Z), seen in the Ka-band ARM zenith radar (KAZR) reflectivity (Fig. 1a). Therefore, the model is initialized with a cloud-free sounding and the cloud forms in response to the radiative cooling, rather than starting the stimulation with a "cloudy" profile and requiring the cloud ice and liquid to adjust to the initial state. The potential temperature and water vapor mixing ratio from the radiosonde and the initial profiles used in the simulations are shown in Fig. 2. Initial water vapor is increased in the region where cloud liquid water was observed after 05:00 Z in order to produce cloud liquid water at the start of the integration. Initial temperature and subgrid turbulent kinetic energy (TKE) are perturbed below the top of the mixed layer with pseudo-random fluctuations with amplitude of $0.1 \mathrm{~K}$ and $0.1 \mathrm{~m}^{2} \mathrm{~s}^{-2}$, respectively.

\subsection{Large-scale forcing}

Large-scale subsidence is specified by integrating the prescribed horizontal wind divergence from the surface upward. Divergence is assumed to be equal to $1.8 \times 10^{-6} \mathrm{~s}^{-1}$ below the inversion and 0 above, following the Solomon et al. (2015) study. This gives a linear increase in large-scale subsidence from 0 at the surface to $1.5 \mathrm{~mm} \mathrm{~s}^{-1}$ at the base

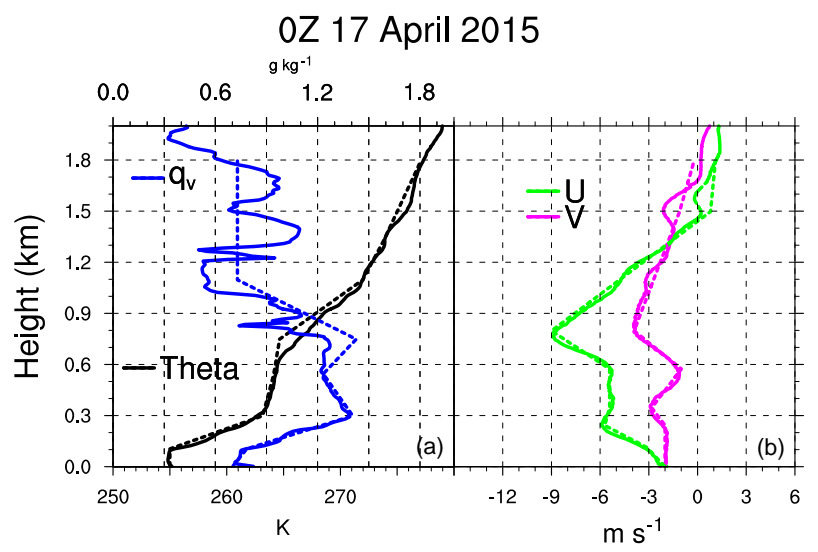

Figure 2. Sounding measured at 00:00 UTC on 17 April 2015 at Oliktok Point, Alaska. (a) Water vapor mixing ratio $\left(q_{\mathrm{v}}\right)$ and potential temperature (theta), in units of $\mathrm{g} \mathrm{kg}^{-1}$ and $\mathrm{K}$, respectively. (b) Zonal wind $(U)$ and meridional wind $(V)$, in units of $\mathrm{ms}^{-1}$. The dashed lines show the initial profiles used in the WRFLES experiments. The dashed line overlying the water vapor mixing ratio is the initial profile for the total water mixing ratio.

of the initial inversion $(z=805 \mathrm{~m})$, above which the largescale vertical wind is constant. Large-scale subsidence is accounted for via a source term for any prognostic variable other than wind components.

Temperature and moisture profiles are nudged to the initial profiles in the top $100 \mathrm{~m}$ of the domain with a timescale of $1 \mathrm{~h}$. Horizontal winds are nudged to the initial profiles at and below the initial inversion base with a timescale of $2 \mathrm{~h}$. Nudging of the horizontal wind components, temperature, and moisture profiles is performed by adding a source term to the prognostic equations for potential temperature, water vapor, and horizontal wind components.

\subsection{Droplet number concentration and $\mathrm{CCN}$ properties}

Because $\mathrm{CCN}$ measurements were not available from Oliktok Point during this time, initial CCN size distributions at every grid point are based on springtime measurements taken during ISDAC (Earle et al., 2011). The accumulation mode observed during ISDAC had a concentration of less than $200 \mathrm{~cm}^{-3}$ (165 $\mathrm{cm}^{-3}$ used in this study), a modal diameter of $0.2 \mu \mathrm{m}$, and a geometric standard deviation of 1.4. Sensitivity studies vary initial $\mathrm{CCN}$ concentration with an arbitrary multiplication factor $C$ (referred to as the $\mathrm{CCN}$ factor). $\mathrm{CCN}$ mean concentration is then treated as a prognostic variable. A prognostic equation for $\mathrm{CCN}$ number concentration has been added to WRFLES,

$$
\begin{aligned}
& \frac{\partial \mathrm{CCN}}{\partial t}+\mathrm{ADV}+\mathrm{DIFF}=\left.\frac{\delta \mathrm{CCN}}{\delta t}\right|_{\text {condensation }} \\
& +\left.\frac{\delta \mathrm{CCN}}{\delta t}\right|_{\text {evaporation }},
\end{aligned}
$$


where ADV represents advection and DIFF represents turbulent diffusion. Condensation is a sink of $\mathrm{CCN}$ and evaporation is a source of CCN. Evaporation (condensation) of one droplet produces (removes) one $\mathrm{CCN}$.

Cloud droplets are activated using resolved and subgrid vertical motion (Morrison and Pinto, 2005) and a log-normal aerosol size distribution (assumed to be ammonium bisulfate and $30 \%$ insoluble by volume) to derive cloud condensation nuclei spectra following Abdul-Razzak and Ghan (2000). As noted in Solomon et al. (2015), because the aerosol number size distribution peaks at a relatively large diameter of $0.2 \mu \mathrm{m}$, the majority of CCN activate into droplets at low supersaturation (at or below $\mathrm{SS}_{w}=0.15 \%$ ) for a reasonable range of aerosol composition assumptions. Since such supersaturations can be generated even by slow updrafts, the sensitivity of droplet number concentration to aerosol composition is expected to be weak. We therefore only include simulations that test the sensitivity to mean $\mathrm{CCN}$ concentrations.

\subsection{Ice nucleation}

Following Solomon et al. (2015), a prognostic equation for INP number concentration $\left(N_{\text {INP }}\right)$ has been added to WRFLES,

$$
\begin{aligned}
& \frac{\partial N_{\mathrm{INP}}}{\partial t}+\mathrm{ADV}+\mathrm{DIFF}=\left.\frac{\delta N_{\mathrm{INP}}}{\delta t}\right|_{\text {activation }} \\
& \quad+\left.\frac{\delta N_{\mathrm{INP}}}{\delta t}\right|_{\text {sublimation }},
\end{aligned}
$$

where ADV represents advection and DIFF represents turbulent diffusion. Activation is also referred to as ice nucleation and sublimation represents a source of INPs, supporting the recycling of these particles.

Eight prognostic equations are integrated for $N_{\text {INP }}$ in equally spaced temperature intervals with nucleation thresholds spanning the range of the in-cloud temperatures $(-20.15$ to $-14.55^{\circ} \mathrm{C}$ ). Therefore, additional INPs become available for activation with decreasing temperature and as the cloud layer cools. INP number concentrations are initially specified at $1.3 \mathrm{~L}^{-1}$ in each bin to produce IWP close to observations for this case. Sensitivity studies vary initial INP concentration with an arbitrary multiplication factor $F$ (referred to as the INP factor).

It is assumed that $50 \%$ of the INPs available in a bin nucleate if the in situ temperature is below the threshold temperature and the local conditions exceed water saturation. Therefore, initial $N_{\text {INP's are a function of the nucleation threshold }}$ temperatures and are independent of the in situ temperature. The in situ temperature in regions of water saturation determines how many INPs are activated. Due to the pristine dendritic nature of the observed crystals and the limited number of INPs, ice shattering and aggregation are neglected in the simulations and sublimation returns one INP per sublimated crystal.
Table 1. Description of simulations completed and discussed in the paper.

\begin{tabular}{lrr}
\hline Simulation name & CCN factor & INP factor \\
\hline Constant ice runs & & \\
\hline ConIce0.5 (red) & $1 / 2$ & 1 \\
Control (black) & 1 & 1 \\
ConIce2.0 (blue) & 2 & 1 \\
\hline Linear ice runs & & \\
\hline LinIce0.5 (red) & $1 / 2$ & $1 / 2$ \\
LinIce2.0 (blue) & 2 & 2 \\
FixCCN2.0 & 2 & 2 \\
\hline
\end{tabular}

$N_{\text {INP }}$ (in units of $\mathrm{L}^{-1}$ ) integrated over the domain in each temperature bin $k$ at time $t$ is equal to

$\bar{N}_{\mathrm{INP}}(k, t)=\iiint N_{\mathrm{INP}}(x, y, z, k, t) \mathrm{d} x \mathrm{~d} y \mathrm{~d} z$.

Upon sublimation, the modification of activation thresholds that can occur for previously nucleated INPs, i.e., preactivation (Roberts and Hallett, 1968), is not considered and $N_{\text {INP's }}$ are returned to each bin $k$ with weighting:

$\mathrm{W}_{k}=\left[\bar{N}_{\mathrm{INP}}(k, 0)-\bar{N}_{\mathrm{INP}}(k, t)\right] / \bar{N}_{\mathrm{INP}}(k, 0)$,

where $\mathrm{W}_{k}$ is normalized such that $\sum \mathrm{W}_{k}=1$. The $\mathrm{W}_{k}$ 's are recalculated each time step. In this way, INPs are recycled preferentially to each of the eight temperature bins from which they originated (Feingold et al., 1996).

\section{Simulations completed}

Simulations completed for this study are listed in Table 1. A simulation with INP and $\mathrm{CCN}$ factors equal to 1.0 is referred to as the Control. To isolate the impact of $\mathrm{CCN}$ perturbations on mixed-phase clouds without a change in ice formation, three simulations were run with $\mathrm{CCN}$ factors $1 / 2,1$, and 2 and INP factors equal to 1.0 (runs ConIce 0.5, Control, and ConIce2.0). To identify the impact of CCN perturbations on mixed-phase clouds when ice formation is a linear function of the $\mathrm{CCN}$ number concentration, two runs were done with INP and CCN factors equal to 2 , one with fixed CCN (FixedCCN2.0) and one with prognostic CCN (LinIce2.0), as well as one run with INP and CCN factors equal to $1 / 2$ (LinIce0.5).

\section{Model results}

\subsection{Control simulation}

The control simulation (CCN and INP factors equal to 1) has IWP and LWP consistent with observations on 17 April 

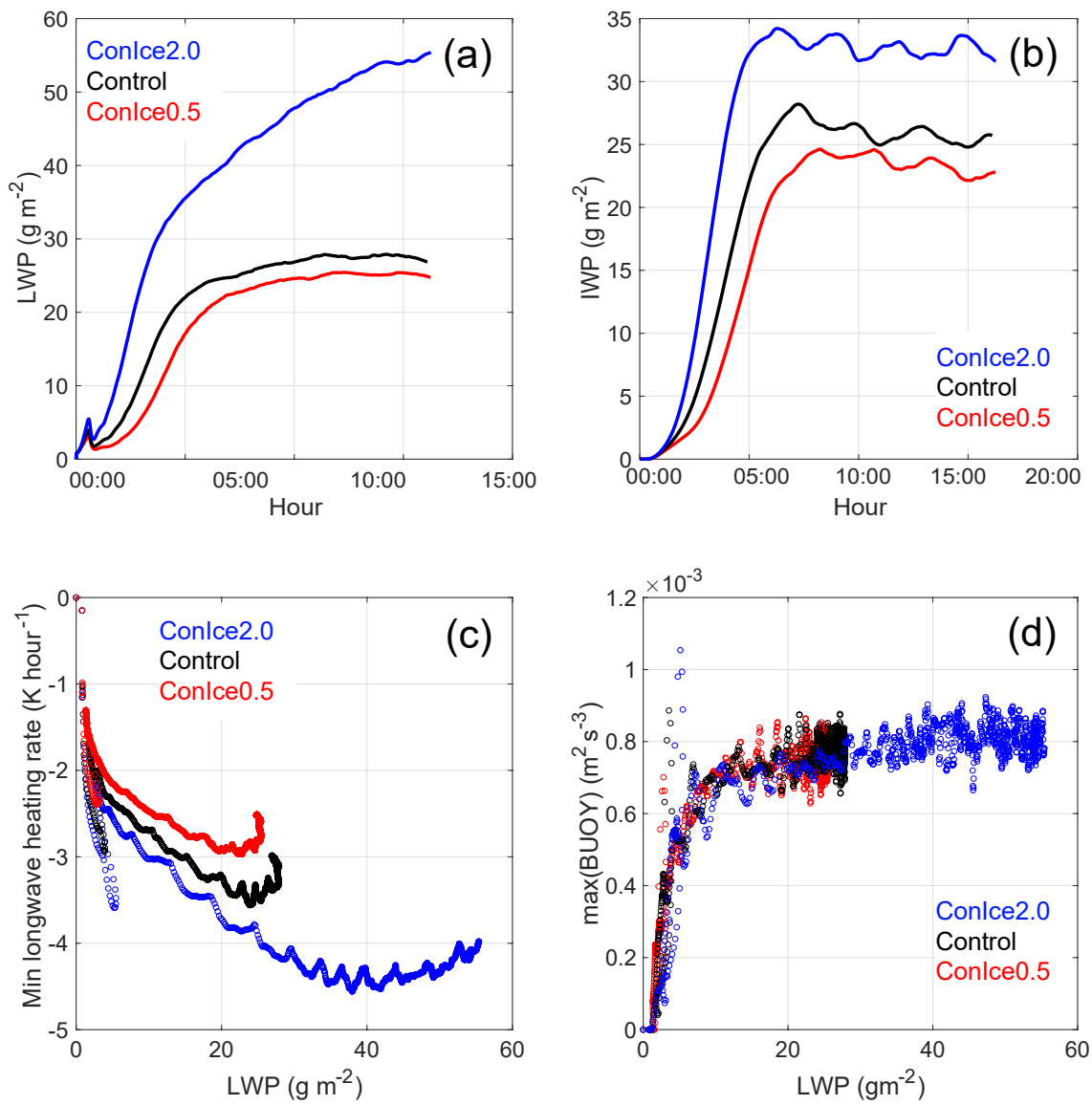

Figure 3. Time series from runs varying CCN concentrations with "constant" ice formation. (a) LWP, in units of $\mathrm{g} \mathrm{m}^{-2}$. (b) IWP, in units of $\mathrm{g} \mathrm{m}^{-2}$. (c) Scatterplot of minimum longwave heating rate vs. LWP, in units of $\mathrm{K} \mathrm{h}^{-1}$ and $\mathrm{g} \mathrm{m}^{-2}$, respectively. (d) Scatterplot of integrated buoyancy vs. LWP, in units of $\mathrm{m}^{3} \mathrm{~s}^{-3}$ and $\mathrm{g} \mathrm{m}^{-2}$, respectively. For INP factors equal to 1.0 and CCN factors 2.0 (blue), 1.0 (black), and 0.5 (red).

2015 (Figs. 1b and 3a) and a cloud system that reaches a steady state after $5 \mathrm{~h}$ with liquid water fractions close to 0.5 . The cloud-driven mixed-layer depth slowly increases over the $16 \mathrm{~h}$ integration, with both cloud top rising and cloud base lowering at a rate of $\sim 5 \mathrm{~m} \mathrm{~h}^{-1}$. However, the cloud system remains decoupled from the surface layer and a surface inversion of $\sim 180 \mathrm{~m}$ in depth is maintained throughout the integration.

Rain forms in the liquid layer (with concentrations less than $0.02 \mathrm{~cm}^{-3}$ ) and evaporates within $200 \mathrm{~m}$ of cloud base. Therefore, the production and impact of rain on this simulation can be neglected. This is true for the sensitivity studies discussed below as well but would not be the case for runs with more limited $\mathrm{CCN}$, which would produce significant precipitation.

Snow does reach the surface during the steady state with a relatively constant flux of $6 \times 10^{-4} \mathrm{~g} \mathrm{~m}^{-2} \mathrm{~s}^{-1}$. Sublimation at the base of the cloud-driven mixed layer reduces the snow water content by $6 \times 10^{-6} \mathrm{~g} \mathrm{~m}^{-3} \mathrm{~s}^{-1}$. In terms of num- ber concentration, this causes the recycling of approximately $1 \mathrm{~L}^{-1} \mathrm{~h}^{-1}$ of INPs back into the cloud-driven mixed layer. Since total ice crystal number concentrations are $1-2 \mathrm{~L}^{-1}$ in the mixed layer over the integration, this indicates that recycling of INPs is playing a significant role in the maintenance of cloud ice in this cloud system (e.g., Solomon et al., 2015).

While the cloud system is maintaining a steady state in cloud ice and liquid, longwave cooling continually cools the cloud-driven mixed layer, contributing to the maintenance of the phase partitioning by increased activation of INPs within the liquid cloud layer and depletion of water vapor within the mixed layer. This cooling is required to maintain the cloud liquid because of the continuous depletion of water vapor and to maintain the cloud ice, since $\sim 2 \mathrm{~L}^{-1}$ of INPs is lost to the surface through precipitation each hour. 

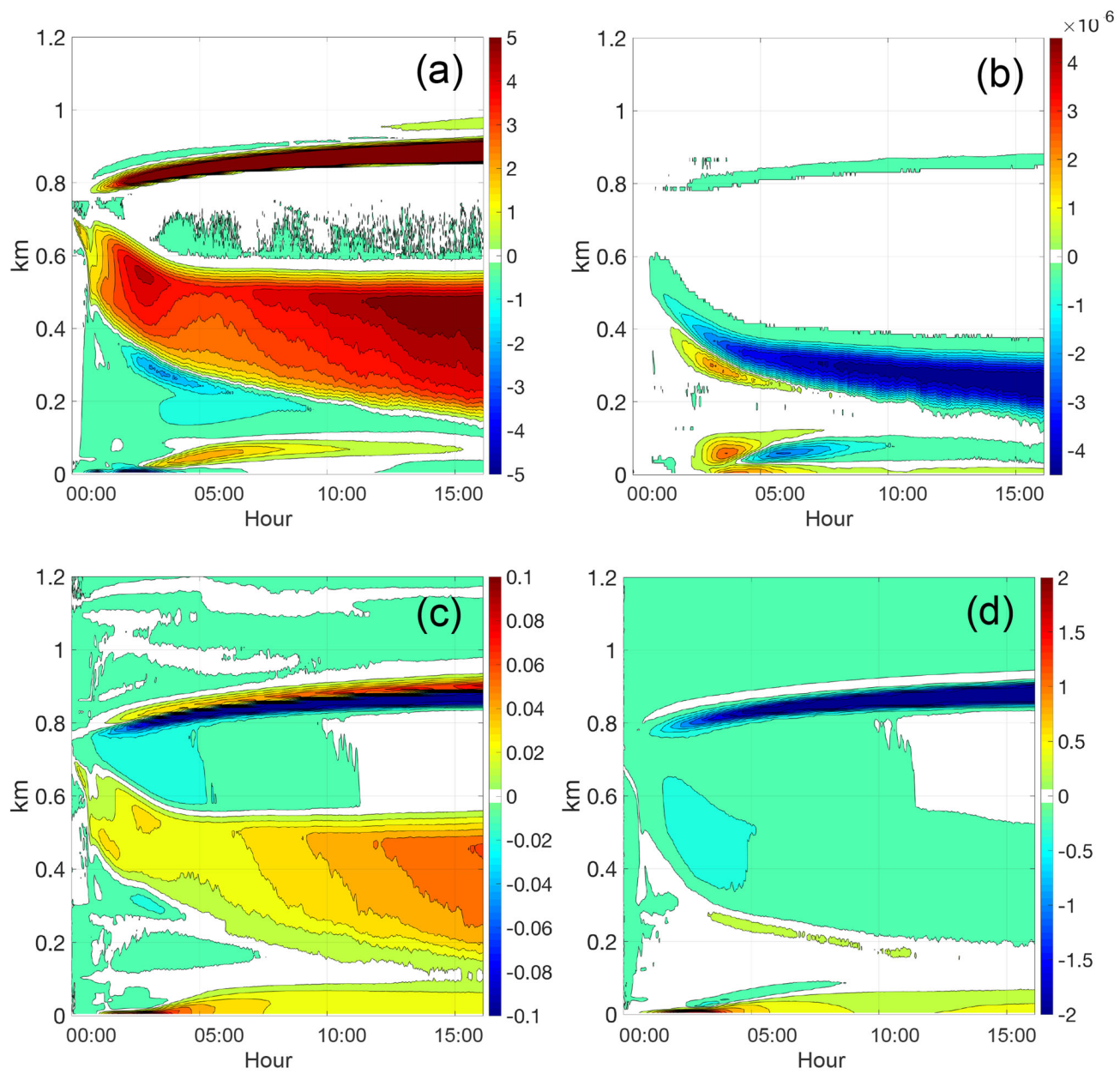

Figure 4. Impact of increasing $\mathrm{CCN}$ by $2 \times$ (ConIce2.0 minus ConIce1.0) on (a) relative humidity, (b) sublimation rate, (c) water vapor mixing ratio, and (d) temperature, in units of percent, $\mathrm{g} \mathrm{m}^{-3} \mathrm{~s}^{-1}, \mathrm{~g} \mathrm{~kg}^{-1}$, and ${ }^{\circ} \mathrm{C}$, respectively.

\subsection{Impact of $\mathrm{CCN}$ perturbations with constant ice formation}

The first set of simulations completed for this study tests the sensitivity of the cloud to perturbations in $\mathrm{CCN}$ concentrations, while keeping INP concentrations fixed (ConIce simulations). Simulations involved increasing and decreasing the initial CCN concentrations by a factor of 2 . These runs provide insight into the impact of CCN perturbations in an Arctic environment with stable stratification near the surface and a weak inversion at cloud top with relatively moist air. Figure 3a shows that increasing the $\mathrm{CCN}$ concentrations has the expected effect at the beginning of the integrations when the cloud layer is optically thin - smaller droplets increase the cloud emissivity and thereby longwave cooling at cloud top, increasing turbulence, supersaturation, and droplet formation. The opposite result is found with decreasing CCN concentrations. For these optically thin cases, radiative cooling is a contribution from the full physical depth of the cloud and the increased cooling rate is therefore an expression of increased total emission of the cloud. Figure $3 b$ shows that this also results in faster vapor deposition rates, resulting in increased ice mass given an increase in CCN. However, this increase in IWP plateaus and slowly decreases after hours 5-6 as ice crystals fall out of the cloud layer and are lost from the system. Decreasing CCN results in slower deposition rates and reduced IWP.

What is unexpected is that the minimum longwave heating rate (or maximum cooling rate) is not exclusively a function of LWP, even after the clouds become optically thick (Fig. 3c). The larger longwave cooling rate associated with a cloud forming in conjunction with elevated $\mathrm{CCN}$ concentrations causes increased total water in the cloud-driven mixed layer (indicating that liquid water increases faster than ice mass), which increases the water vapor mixing ratio below the liquid layer, increasing relative humidity in the mixed layer below the liquid layer (see Fig. 4a). The IWP shows larger temporal variability than the LWP, potentially due to larger sensitivity to small perturbations in relative humidity. 

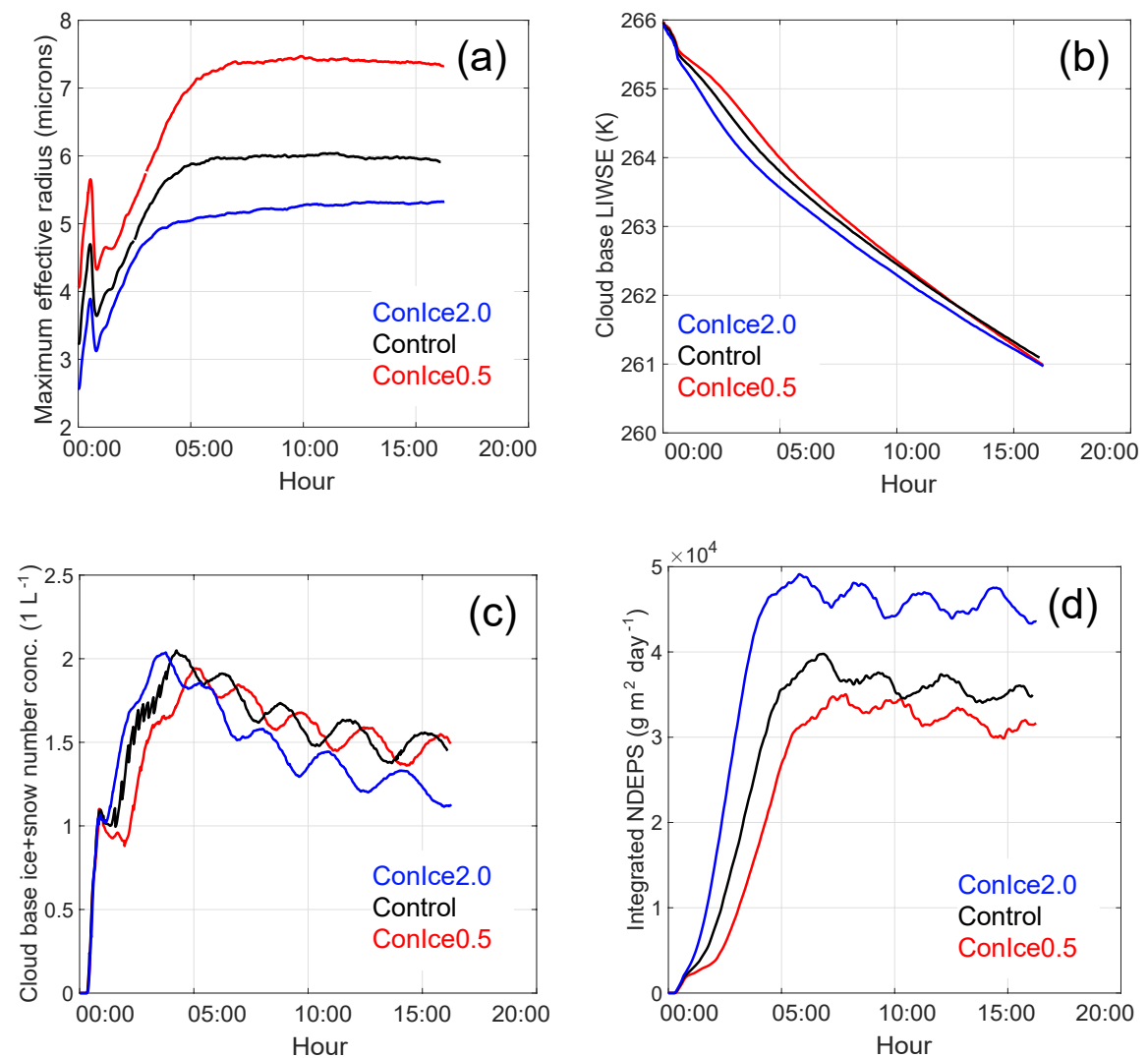

Figure 5. Time series from runs varying $\mathrm{CCN}$ concentrations with constant ice formation. (a) Maximum effective radius, in units of microns. (b) Cloud mixed-layer liquid-ice water static energy, in units of K. (c) Cloud base ice plus snow number concentration, in units of $\mathrm{L}^{-1}$. (d) Vertically integrated net deposition rate, in units of $\mathrm{g} \mathrm{m}^{-2}$ day ${ }^{-1}$. For INP factors equal to 1.0 and CCN factors 0.5 (red), 1.0 (black), and 2.0 (blue).

Increasing $\mathrm{CCN}$ causes the cloud top to rise and the cloud base to lower faster while keeping the maximum buoyancy relatively unchanged; the maximum buoyancy as a function of LWP is similar for ConIce2.0 and Control, with Control approximately $1 \times 10^{-4}$ less than ConIce 2.0 for LWP less than $17 \mathrm{~g} \mathrm{~m}^{-2}$ (Fig. 3d). The deepening of the cloud layer for an increase in $\mathrm{CCN}$ causes the impact of $\mathrm{CCN}$ on maximum droplet size to persist throughout the integration (Fig. 5a), even though LWP is increasing more rapidly (Fig. 3a).

The ConIce set of simulations was designed to identify the impact of CCN variability on phase partitioning and cloud dynamics for a relatively constant magnitude of cloud ice number concentration. This is seen to be the case in Fig. 5c; however, interestingly, processes such as sublimation cause ConIce2.0 to have less total cloud ice number concentration than the other two runs (see Fig. 4a-d), since a reduction in sublimation causes more INPs to fall out of the mixed layer and less recycling of INPs in the cloud layer. However, the differences in relative humidity also play a role here and therefore the sublimation rate is not just a function of the ice present. Increasing $\mathrm{CCN}$ causes more rapid mixed-layer cooling (Figs. 4b and 5b) and deeper mixed-layer depths, and therefore larger net deposition rates (Fig. 5d) and larger IWPs (Fig. 3b).

\subsection{Impact of $\mathrm{CCN}$ perturbations with linear ice formation}

A second set of simulations was completed adding an additional degree of realism to the simulations by scaling INP concentrations with the $\mathrm{CCN}$ concentration, i.e., equal INP and $\mathrm{CCN}$ factors (LinIce simulations). This was done in order to represent the case of a polluted air mass with equal relative increases in CCN and INPs. The fraction of INPs to $\mathrm{CCN}$ evolves in time as cloud ice forms and precipitates, sublimates below the cloud base, and advects back into the cloud layer with the cloud-driven vertical motions.

Figure 6 shows the sensitivity of the LWP and IWP to an increase and decrease in CCN and INPs by a factor of 2 . Similar to the ConIce runs, the increase in LWP begins to slow when IWP exceeds $20 \mathrm{~g} \mathrm{~m}^{-2}$. Before hour 5 the ConIce and LinIce runs have similar trajectories. After hour 5 these runs diverge; decreasing CCN and INP factors in LinIce results 

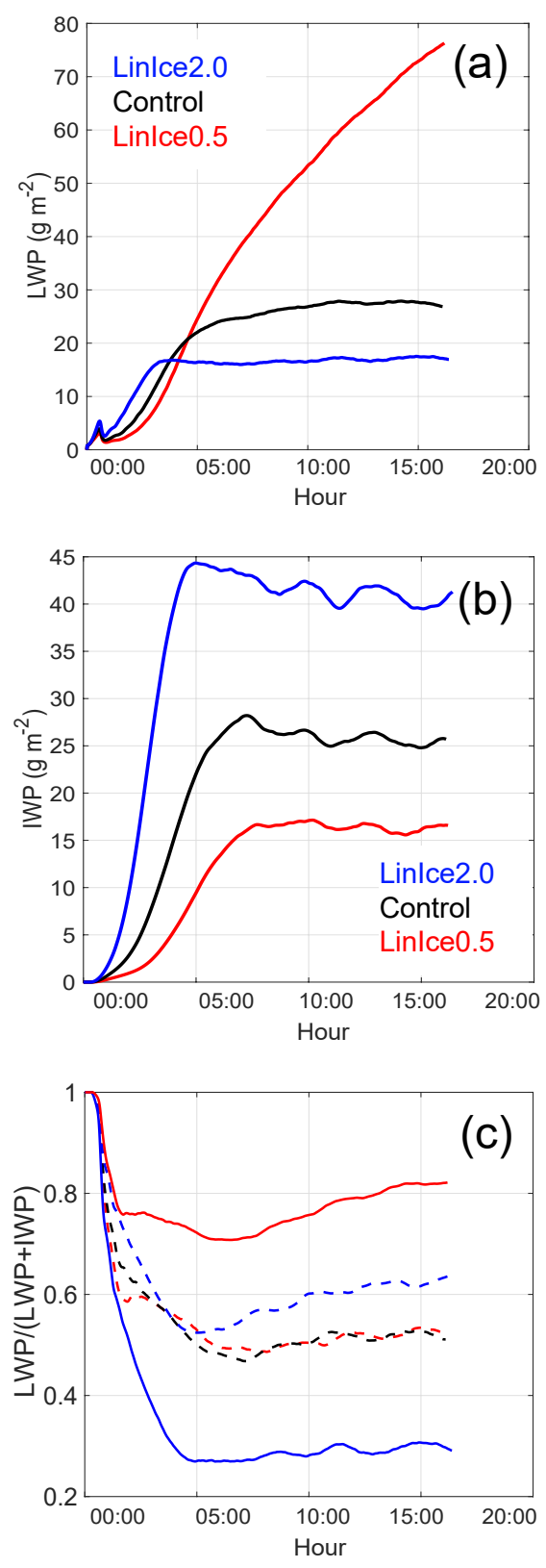

Figure 6. Time series from runs varying $\mathrm{CCN}$ concentrations with "linear" ice formation. (a) LWP, in units of $\mathrm{g} \mathrm{m}^{-2}$. (b) IWP, in units of $\mathrm{g} \mathrm{m}^{-2}$. (c) Liquid water fraction for ConIce (solid) and LinIce (dashed). For CCN and INP factors 0.5 (red), 1.0 (black), and 2.0 (blue).

in larger LWP because of the dominating effect of INP variability on water vapor availability. Increasing CCN and INP factors from 0.5 to 1.0 results in a $63 \%$ decrease in LWP at hour 15.

The LinIce runs highlight the extreme sensitivity of phase partitioning between cloud liquid and ice to very small changes in INP concentrations. For these simulations, there is a 5-orders-of-magnitude difference between $\mathrm{CCN}$ and
INP concentrations, with the scaling done on a percentage basis relative to the absolute amount. In other words, a change in INPs from 1 to $2 \mathrm{~L}^{-1}$ has a substantially larger effect on cloud phase than a change in CCN from 10000 to $20000 \mathrm{~L}^{-1}$, despite the latter change obviously being much more extreme from the perspective of aerosol number concentration. The $\mathrm{CCN}$ variability in the LinIce runs causes a $50 \%$ increase in droplet effective radius for a decrease in $\mathrm{CCN}$ by a factor of 2 (Fig. 7a). These changes are of the same sign as the ConIce runs but are larger due to the additional impact of INP variability on water vapor available for condensation. Similarly, the reduction of cloud droplet size related to the presence of elevated aerosol concentrations is exacerbated when both INP and CCN concentrations increase due to the combination of more nucleated droplets (on $\mathrm{CCN}$ ) and increased water vapor deposition (on ice crystals generated by the elevated INP concentrations). However, the impact of the changes in droplet effective radius is small relative to the impact of INP variability on the dynamics of the clouddriven mixed layer after approximately hour 4 . For example, after hour 7 the LinIce 0.5 run has a colder cloud-driven mixed layer than the Control and LinIce2.0 runs (Fig. 7b), whereas ConIce2.0 had a colder cloud-driven mixed layer than ConIce0.5 (Fig. 5b).

The ratio of INPs among the LinIce runs stays relatively constant for the $16 \mathrm{~h}$ integrations (Fig. 7c), indicating that differences in sublimation (INP recycling) and ice fall speeds do not produce appreciably different ice crystal number concentrations in the cloud-driven mixed layer. However, larger deposition rates in the cloud-driven mixed layer due to increased ice number concentrations (Fig. 7d) result in larger ice water mixing ratios (a $31 \%$ increase between ConIce 2.0 and LinIce2.0), even though mixed-layer temperatures are warmer for an increase in CCN and INP factors, indicating that vapor deposition on snow (NDEPS) is dominant relative to ice number in controlling IWP.

Allowing both prognostic CCN and INPs reveals interesting layering of aerosol distributions that results from differential liquid and ice processes. This is seen in Fig. 8, where the turbulent advection of droplets into the cloud-top inversion causes larger $\mathrm{CCN}$ concentrations above the liquid cloud layer than below (Fig. 8a). The opposite result is found for INPs, where gravitational settling of ice crystals and the subsequent sub-cloud sublimation produces locally elevated INP concentrations in the lowest $200 \mathrm{~m}$ (Fig. 8b). This layering of aerosols causes larger entrainment of $\mathrm{CCN}$ at cloud top and larger entrainment of INPs at the mixed-layer base as the mixed layer deepens. As was demonstrated in Solomon et al. (2015), the increase in INPs at the base of the mixed layer contributed to the maintenance of the phase partitioning by making more INPs available for activation as ice crystals as the mixed layer deepens.

This layering of aerosols, with increased $\mathrm{CCN}$ above the liquid layer and increased INPs below the cloud-driven mixed layer, causes interesting differences between runs with 

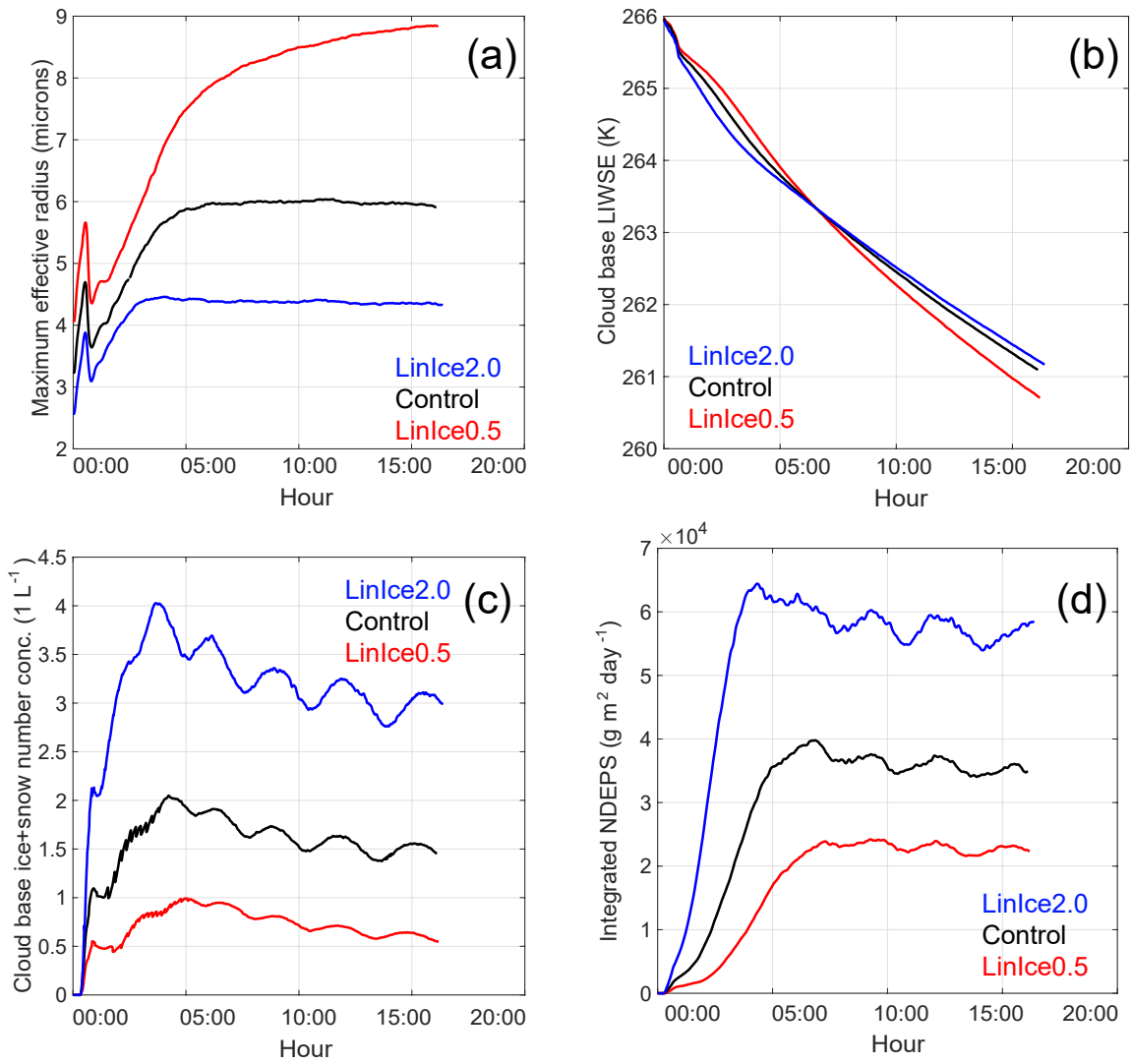

Figure 7. Time series from runs varying CCN concentrations with linear ice formation. (a) Maximum effective radius, in units of microns. (b) Cloud mixed-layer liquid-ice water static energy, in units of $\mathrm{K}$. (c) Cloud base ice plus snow number concentration, in units of $\mathrm{L}^{-1}$. (d) Vertically integrated net deposition rate, in units of $\mathrm{g} \mathrm{m}^{-2} \mathrm{day}^{-1}$. For CCN and INP factors 0.5 (red), 1.0 (black), and 2.0 (blue).

and without prognostic CCN (Fig. 9). The increase in CCN above the liquid layer causes increased entrainment of $\mathrm{CCN}$ at cloud top (Fig. 9a), decreasing the droplet effective radius, increasing the longwave cooling (Fig. 9b), and increasing the deposition rate and ice water mixing ratio (Fig. 9c). Ultimately, these differences result in stronger buoyancy with the cloud layer (Fig. 9d), where buoyancy is increased by up to $10 \%$.

\section{Summary and discussion}

In this study we use idealized large-eddy simulations to quantify the relative impact of CCN and INP perturbations on the phase partitioning and dynamics of AMPS. The modeling framework developed in Solomon et al. (2015) to study the recycling of INPs has been extended to include prognostic $\mathrm{CCN}$. The first set of simulations was designed to investigate the impact of relatively small perturbations in $\mathrm{CCN}$ compared to studies such as Morrison et al. (2008) and Kravitz et al. (2014) in mixed-phase conditions with essentially constant INPs on phase partitioning and cloud dynamics. It is found that increasing $\mathrm{CCN}$ by a factor of 2 increases LWP by $60 \%-100 \%$, while decreasing CCN by a factor of 2 reduces LWP by less than $8 \%$, i.e., the impact is highly nonlinear. This change stems primarily from an increase in cloud longwave emissivity and associated increase in cloud-top cooling rates, connected to a decrease in droplet size. This elevated cooling rate causes the cloud-driven mixed layer to cool and deepen more rapidly. However, interestingly, this difference persists even when the cloud radiates as a blackbody, highlighting the influence of early changes to the system.

The sensitivity to CCN in this study is significantly larger than that found in the M-PACE case study by Morrison et al. (2008) and the ISDAC case study by Kravitz et al. (2014). The M-PACE and ISDAC case studies are useful as examples of the extreme range of conditions under which mixed-phase clouds exist. M-PACE took place in October over open water with large fluxes of heat and momentum from the surface into the cloud layer, while ISDAC took place during the spring when the Arctic Ocean was essentially ice covered and the cloud layer was decoupled from the surface layer.

In the M-PACE case study, increasing $\mathrm{CCN}$ by a factor of 5-6 resulted in an increase in LWP by $20 \%$ and a decrease in 

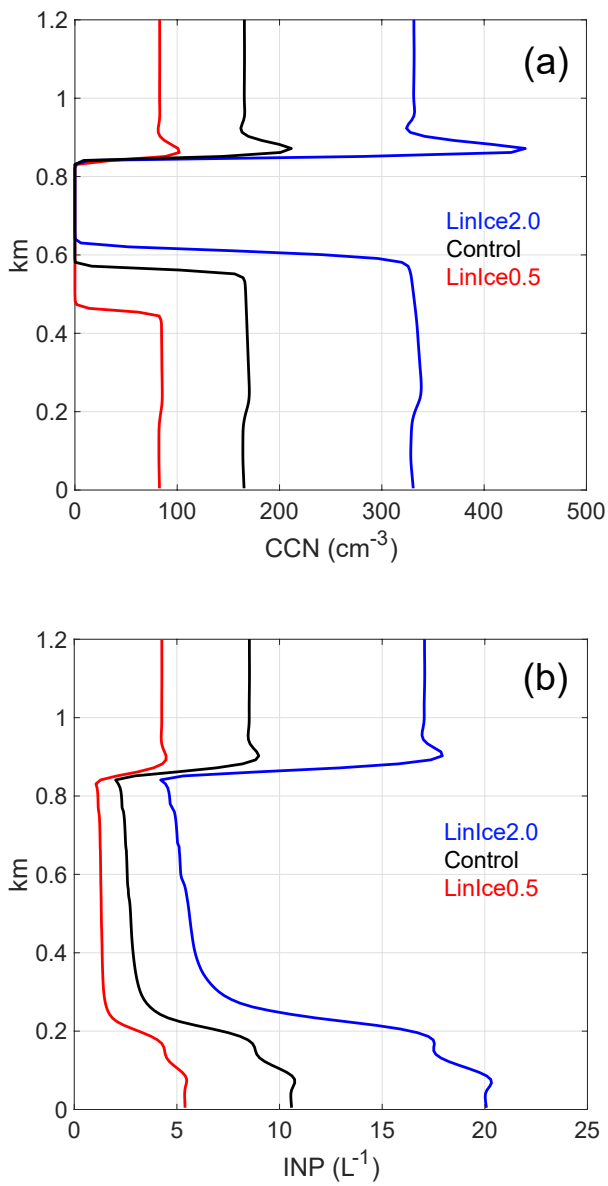

Figure 8. (a) $\mathrm{CCN}$ and (b) INPs in linear ice runs at hour 10, in units of $\mathrm{cm}^{-3}$ and $\mathrm{L}^{-1}$, respectively. For $\mathrm{CCN}$ and INP factors 0.5 (red), 1.0 (black), and 2.0 (blue).

IWP by $60 \%$. In the ISDAC case study, increasing CCN by a factor of 4 resulted in similar LWP and IWP until hour 12 when the more pristine cloud collapsed. A very interesting difference between this study and the two previous studies is that both the M-PACE and ISDAC studies found IWP to decrease when CCN was increased, while this study finds an increase in IWP due to increased longwave cooling and larger deposition rates. For the ISDAC case study this may be due to the continuous decrease in droplet number concentration, which would cause the cloud dynamics to spin down. This study also finds a significantly larger sensitivity to INPs than the M-PACE case study. The M-PACE case study found that a $10 \times$ increase in INPs resulted in a $120 \%$ increase in IWP and a $23 \%$ decrease in LWP, while this study finds increasing INPs by $2 \times$ results in a $60 \%$ increase in IWP and a $36 \%$ decrease in LWP. These differences need to be investigated further to identify the relative impact of different environmental conditions and model physics.

The differences between this study and the M-PACE and ISDAC studies are due in part to the different environmen-
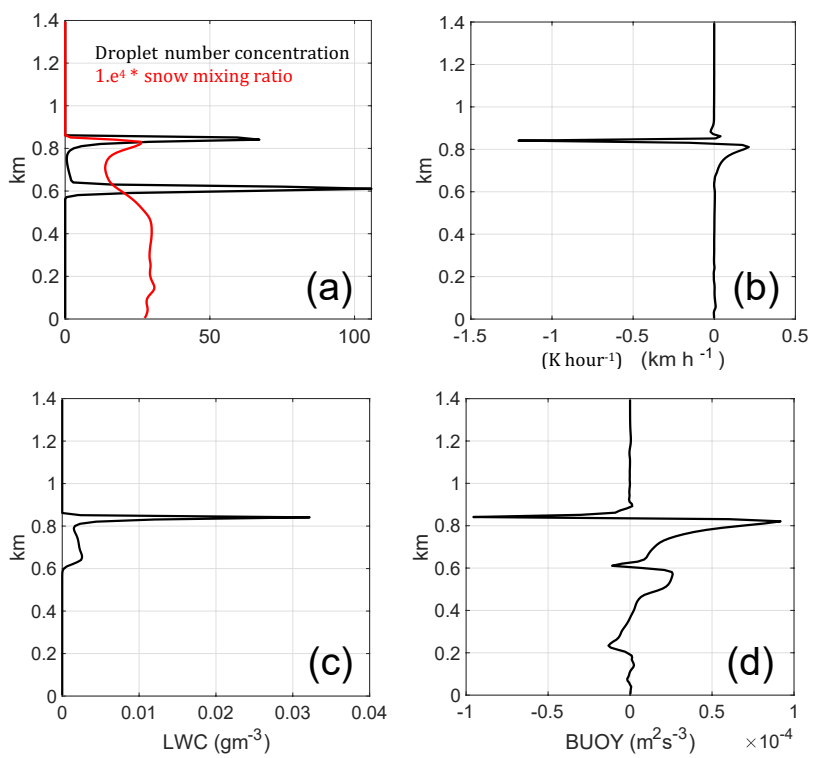

Figure 9. Impact of prognostic CCN (LinIce2.0-FixCCN2.0) over hour 10. (a) Droplet number concentration (black) and snow mixing ratio (red), in units of $\mathrm{cm}^{-3}$ and $1 \times 10^{4} \mathrm{~g} \mathrm{~kg}^{-1}$, respectively. (b) Longwave radiative heating rate, in units of $\mathrm{Kh}^{-1}$. (c) Liquid water content, in units of $\mathrm{g} \mathrm{m}^{-3}$. (d) Buoyancy, in units of $\mathrm{m}^{2} \mathrm{~s}^{-3}$.

tal conditions but the different sensitivities to both $\mathrm{CCN}$ and INPs are also due to the different parameterizations used in these models. Both the M-PACE and ISDAC studies essentially hold INPs fixed, while this study does not constrain INPs other than specifying an initial value. This allows for the vertical redistribution of particles throughout the domain, resulting in feedbacks between ice and droplet properties and cloud dynamics not included in the two previous case studies and in many climate and weather-scale models.

Additionally, the inclusion of prognostic CCN and INPs reveals a number of feedbacks that buffer the cloud system from collapsing. The first buffering feedback is the recycling of INPs, which was the focus of the Solomon et al. (2015) study. The IWP, and therefore phase partitioning between cloud ice and liquid, cannot be maintained without this feedback. However, the reservoir of INPs below the mixed layer would be depleted if cloud-driven mixed layer became coupled to the surface layer. The second interesting buffering feedback is the layering of the aerosols, with increased concentrations of $\mathrm{CCN}$ above cloud top and increased concentrations of INPs at the base of the mixed layer. As demonstrated in this paper, this layering contributes to the maintenance of the cloud liquid, which ultimately drives the dynamics of the cloud system. A third buffering feedback is the thinning of the liquid layer when INP concentrations are increased. The occurrence of this thinning does not produce complete glaciation, but instead causes the mixed-phase clouds to ra- 
diate as grey bodies and the radiative properties of the clouds to be more sensitive to aerosol perturbations.

Ultimately, enhanced observations of the vertical structure of cloud microphysics and aerosol properties are required. Recent work by the DOE ARM program to operate unmanned aircraft and tethered balloons has provided new perspectives on these quantities and the dynamic and thermodynamic conditions supporting these cloud systems (de Boer et al., 2018). Such observational efforts should continue to be pursued further to help constrain the sensitivities demonstrated by numerical studies as presented here.

Data availability. The model code and data used in this study are available from the corresponding author upon request (amy.solomon@noaa.gov).

Author contributions. AS and GdB conducted the study design. AS carried out the modeling work. Data analysis was done by AS and GdB. AS wrote the manuscript. JMC, AM, MDS, MM, and CC interpreted data and edited the manuscript. All the authors commented on and discussed the manuscript.

Competing interests. The authors declare that they have no conflict of interest.

Acknowledgements. This research was supported by the US Department of Energy (DOE) Atmospheric Systems Research (ASR) program (DE-SC0013306) and the National Oceanic and Atmospheric Administration (NOAA) Physical Sciences Division (PSD). Additionally, measurements used in this study were supported by the US Department of Energy Atmospheric Radiation Measurement (ARM) program. The authors thank Graham Feingold for insightful comments.

Edited by: Christopher Hoyle

Reviewed by: two anonymous referees

\section{References}

Abdul-Razzak, H. and Ghan, S. J.: A parameterization of aerosol activation 2. Multiple aerosol types, J. Geophys. Res., 105, 68376844, 2000.

Albrecht, B. A.: Aerosols, cloud microphysics, and fractional cloudiness, Science, 245, 1227-1230, 1989.

Bergeron, T.: On the physics of clouds and precipitation, in: Proces Verbaux de l'Association de Meteorologie, edited by: Duport, P., 156-178, International Union of Geodesy and Geophysics, 1935.

Curry, J. A. and Ebert, E. E.: Annual cycle of radiation fluxes over the Arctic Ocean: Sensitivity to cloud optical properties, J. Climate., 5, 1267-1280, 1992.

Curry, J. A., Schramm, J. L., and Ebert, E. E.: Impact of clouds on the surface radiation balance of the ocean, Meteor. Atmos. Phys., 51, 197-217, 1993.
Cziczo, D., Froyd, K., Gallavardin, S., Moehler, O., Benz, S., Saathoff, H., and Murphy, D.: Deactivation of ice nuclei due to atmospherically relevant surface coatings, Environ. Res. Lett., 4, 044013, https://doi.org/10.1088/1748-9326/4/4/044013, 2009.

de Boer, G., Morrison, H., Hildner, R., and Shupe, M. D.: Evidence of liquid-dependent ice nucleation in high-latitude stratiform clouds from surface remote sensors, Geophys. Res. Lett., 38, L01803, https://doi.org/10.1029/2010GL046016, 2011.

de Boer, G., Ivey, M., Schmid, B., Lawrence, D., Dexheimer, D., Mei, F., Hubbe, J., Bendure, A., Hardesty, J., Shupe, M. J., McComiskey, A., Telg, H., Schmitt, C., Matrosov, S., Brooks, I., Creamean, J. M., Solomon, A., Turner, D. D., Williams, C., Maahn, M., Argrow, B., Palo, S., Long, C. N., Gao, R.-S., and Mather, J.: A Bird's-Eye View: Development of an Operational ARM Unmanned Aerial Capability for Atmospheric Research in Arctic Alaska, B. Am. Meteorol. Soc., 99, 1197-1212, https://doi.org/10.1175/BAMS-D-17-0156.1, 2018.

DeMott, P. J., Prenni, A. J., Liu, X., Petters, M. D., Twohy, C. H., Richardson, M. S., Eidhammer, T., Kreidenweis, S. M., and Rogers, D. C.: Predicting global atmospheric ice nuclei distributions and their impacts on climate, P. Natl. Acad. Sci. USA, 107, 11217-11222, https://doi.org/10.1073/pnas.0910818107, 2010.

DeMott, P. J., Prenni, A. J., McMeeking, G. R., Sullivan, R. C., Petters, M. D., Tobo, Y., Niemand, M., Möhler, O., Snider, J. R., Wang, Z., and Kreidenweis, S. M.: Integrating laboratory and field data to quantify the immersion freezing ice nucleation activity of mineral dust particles, Atmos. Chem. Phys., 15, 393-409, https://doi.org/10.5194/acp-15-393-2015, 2015.

Dyer, A. J. and Hicks, B. B.: Flux-gradient relationships in the constant flux layer, Q. J. Roy. Meteor. Soc., 96, 715-721, 1970.

Earle, M. E., Liu, P. S., Strapp, J. W., Zelenyuk, A., Imre, D., McFarquhar, G. M., Shantz, N. C., and Leaitch, W. R.: Factors influencing the microphysics and radiative properties of liquid-dominated Arctic clouds: Insight from observations of aerosol and clouds during ISDAC, J. Geophys. Res.-Atmos., 116, D00T09, https://doi.org/10.1029/2011jd015887, 2011.

Feingold, G., Kreidenweis, S. M., Stevens, B., and Cotton, W. R.: Numerical simulation of stratocumulus processing of cloud condensation nuclei through collision-coalescence, J. Geophys. Res., 101, 21391-21402, 1996.

Findeisen, W.: Kolloid-Meteorologische, 2nd edn., American Meteorological Society, 1938.

Garimella, S., Rothenberg, D. A., Wolf, M. J., David, R. O., Kanji, Z. A., Wang, C., Rösch, M., and Cziczo, D. J.: Uncertainty in counting ice nucleating particles with continuous flow diffusion chambers, Atmos. Chem. Phys., 17, 10855-10864, https://doi.org/10.5194/acp-17-10855-2017, 2017.

Garrett, T. and Zhao, C.: Increased Arctic cloud longwave emissivity associated with pollution from mid-latitudes, Nature, 440, 787-789, 2006.

Girard, E. and Sokhandan, A. N.: Relative importance of acid coating on ice nuclei in the deposition and contact modes for wintertime Arctic clouds and radiation, Meteorol. Atmos. Phys., 123, 81-92, 2014.

Hobbs, P. and Rangno, A.: Microstructures of low and middle-level clouds over the Beaufort Sea, Q. J. Roy. Meteor. Soc., 124, 20352071, 1998.

Intrieri, J. M., Shupe, M. D., Uttal, T., and McCarty, B. J.: An annual cycle of Arctic cloud characteristics observed by 
radar and lidar at SHEBA, J. Geophys. Res., 107, 8030, https://doi.org/10.1029/2000JC000423, 2002.

Kravitz, B., Wang, H., Rasch, P. J., Morrison, H., and Solomon, A. B.: Process-model simulations of cloud albedo enhancement by aerosols in the Arctic, Philos. T. Roy. Soc. A, https://doi.org/10.1098/rsta.2014.0052, 2014.

Lance, S., Shupe, M. D., Feingold, G., Brock, C. A., Cozic, J., Holloway, J. S., Moore, R. H., Nenes, A., Schwarz, J. P., Spackman, J. R., Froyd, K. D., Murphy, D. M., Brioude, J., Cooper, O. R., Stohl, A., and Burkhart, J. F.: Cloud condensation nuclei as a modulator of ice processes in Arctic mixed-phase clouds, Atmos. Chem. Phys., 11, 8003-8015, https://doi.org/10.5194/acp11-8003-2011, 2011.

McFarquhar, G. M., Zhang, G., Poellot, M. R., Kok, G. L., McCoy, R., Tooman, T., and Heymsfield, A. J.: Ice properties of single layer stratocumulus during the Mixed-Phase Arctic Cloud Experiment (MPACE). Part I: Observations, J. Geophys. Res., 112, D24202, https://doi.org/10.1029/2007JD008646, 2007.

McFarquhar, G. M., Ghan, S., Verlinde, J., Korolev, A., Strapp, J. W., Schmid, B., Tomlinson, J. M., Wolde, M., Brooks, S. D., Cziczo, D., Dubey, M. K., Fan, J., Flynn, C., Gultepe, I., Hubbe, J., Gilles, M. K., Laskin, A., Lawson, P., Leaitch, W. R., Liu, P., Liu, X., Lubin, D., Mazzoleni, C., MacDonald, A. M., Moffet, R. C., Morrison, H., Ovchinnikov, M., Shupe, M. D., Turner, D. D., Xie, S., Zelenyuk, A., Bae, K., Freer, M., and Glen, A.: Indirect and semi-direct aerosol campaign: The impact of arctic aerosols on clouds, B. Am. Meteorol. Soc., 92, 183-201, https://doi.org/10.1175/2010BAMS2935.1, 2011.

Mlawer, E. J., Taubman, S. J., Brown, P. D., Iacono, M. J., and Clough, S. A.: Radiative transfer for inhomogeneous atmospheres: RRTM, a validated correlated-k model for the longwave, J. Geophys. Res., 102, 16663-16682, 1997.

Morrison, H. and Pinto, J. O.: Mesoscale modeling of springtime Arctic mixed-phase stratiform clouds using a new two-moment bulk microphysics scheme, J. Atmos. Sci., 62, 3683-3704, 2005.

Morrison, H., Pinto, J. O., Curry, J. A., and McFarquhar, G. M.: Sensitivity of modeled arctic mixed-phase stratocumulus to cloud condensation and ice nuclei over regionally varying surface conditions, J. Geophys. Res., 113, D05203, https://doi.org/10.1029/2007JD008729, 2008.

Morrison, H., Thompson, G., and Tatarskii, V.: Impact of cloud microphysics on the development of trailing stratiform precipitation in a simulated squall line: Comparison of one- and two-moment schemes, Mon. Weather Rev., 137, 991-1007, https://doi.org/10.1175/2008MWR2556.1, 2009.

Murray, B. J., O’Sullivan, D., Atkinson, J. D., and Webb, M. E.: Ice nucleation by particles immersed in supercooled cloud droplets, Chem. Soc. Rev., 41, 6519-6554, 2012.

Paulson, C. A.: The mathematical representation of wind speed and temperature profiles in the unstable atmospheric surface layer, J. Appl. Meteorol., 9, 857-861, 1970.
Pincus, R. and Baker, M. B.: Effect of precipitation on the albedo susceptibility of marine boundary layer clouds, Nature, 372, 250-252, 1994.

Pruppacher, H. R. and Klett, J. D.: Microphysics of Clouds and Precipitation, 2nd edn., Kluwer, Dordrecht, Netherlands, 1997.

Roberts, P. and Hallett, J.: A laboratory study of the ice nucleating properties of some mineral particulates, Q. J. Roy. Meteor. Soc., 94, 25-34, https://doi.org/10.1002/qj.49709439904, 1968.

Shupe, M. D. and Intrieri, J. M.: Cloud radiative forcing of the Arctic surface: The influence of cloud properties, surface albedo, and solar zenith angle, J. Climate, 17, 616-628, 2004.

Solomon, A., Feingold, G., and Shupe, M. D.: The role of ice nuclei recycling in the maintenance of cloud ice in Arctic mixedphase stratocumulus, Atmos. Chem. Phys., 15, 10631-10643, https://doi.org/10.5194/acp-15-10631-2015, 2015.

Stevens, B. and Feingold, G.: Untangling aerosol effects on clouds and precipitation in a buffered system, Nature, 461, 607-613, 2009.

Stevens, B., Cotton, W., Feingold, G., and Moeng, C.: Large-eddy simulations of strongly precipitating, shallow, stratocumulustopped boundary layers, J. Atmos. Sci., 55, 3616-3638, 1998.

Sullivan, R. C., Miambres, L., DeMott, P. J., Prenni, A. J., Carrico, C. M., Levin, E. J. T., and Kreidenweis, S. M.: Chemical processing does not always impair heterogeneous ice nucleation of mineral dust particles, Geophys. Res. Lett., 37, L24805, https://doi.org/10.1029/2010GL045540, 2010.

Tewari, M., Chen, F., Wang, W., Dudhia, J., LeMone, M. A., Mitchell, K., Ek, M., Gayno, G., Wegiel, J., and Cuenca, R. H.: Implementation and verification of the unified NOAH land surface model in the WRF model, 20th conference on weather analysis and forecasting/16th conference on numerical weather prediction, 11-15, 2004.

Twomey, S.: Influence of pollution on shortwave albedo of clouds, J. Atmos. Sci., 34, 1149-1152, 1977.

Webb, E. K.: Profile relationships: The log-linear range, and extension to strong stability, Q. J. Roy. Meteor. Soc., 96, 67-90, 1970.

Wegener, A.: Thermodynamik der Atmosphaäe, J. A. Barth, Leipzig, 331 pp., 1911.

Westbrook, C. D. and Illingworth, A. J.: The formation of ice in a long-lived supercooled layer cloud, Q. J. Roy. Meteor. Soc., 139, 2209-2221, https://doi.org/10.1002/qj.2096, 2013.

Yamaguchi, T. and Feingold, G.: Technical note: Large-eddy simulation of cloudy boundary layer with the Advanced Research WRF model, J. Adv. Model. Earth Syst., 4, M09003, https://doi.org/10.1029/2012MS000164, 2012.

Zhang, T., Stamnes, K., and Bowling, S. A.: Impact of clouds on surface radiative fluxes and snowmelt in the Arctic and Subarctic, J. Climate., 9, 2110-2123, 1996. 